\title{
From Water Poverty to Water Prosperity-A More Participatory Approach to Studying Local Water Resources Management
}

\author{
Julie Wilk and Anna Jonsson
}

\section{Linköping University Post Print}

N.B.: When citing this work, cite the original article.

The original publication is available at www.springerlink.com:

Julie Wilk and Anna Jonsson, From Water Poverty to Water Prosperity-A More Participatory Approach to Studying Local Water Resources Management, 2013, Water resources management, (27), 3, 695-713.

http://dx.doi.org/10.1007/s11269-012-0209-8

Copyright: Springer Verlag (Germany) http://www.springerlink.com/?MUD=MP

Postprint available at: Linköping University Electronic Press http://urn.kb.se/resolve?urn=urn:nbn:se:liu:diva-89159 


\title{
From Water Poverty to Water Prosperity - a more participatory approach to studying local water resources management
}

\section{Julie Wilk, Anna C. Jonsson}

\begin{abstract}
The Water Poverty Index (WPI), a tool designed for integrated analysis of water issues, was set-up in a community in Madhya Pradesh, India through a transparent and participatory process. Though the aim of the WPI is to primarily use existing statistical data, quantitative information from census and local records was combined with qualitative data from community interviews and participatory exercises. The inclusion of community chosen indicators and the adjustment of values so that higher numbers represent water prosperity rather than water poverty, led to the Water Prosperity Index $\left(\mathrm{WPI}^{+}\right)$. The $\mathrm{WPI}^{+}$score was contrasted with the WPI at community level. It was also calculated for two community areas with different caste and socioeconomic characteristics and weighted separately according to water issues prioritized by men and women. The $\mathrm{WPI}^{+}$revealed a great difference in water access between the two areas and in prioritized issues between men and women illustrated in the importance of appropriate spatial representation and gender sensitive assessment for revealing important disparities. Results also showed that highly aggregated data hide these differences making it more difficult to target the most vulnerable groups when planning measures to increase equitable water allocation. While quantitative data revealed an important perspective of the water situation, qualitative data about adequacy of resources, services or institutions, improved understanding of which issues to prioritize. A valid and useful community water index must be based on representative participation, transparency and local influence on the methodology and subsequent results.
\end{abstract}




\section{Introduction}

As populations increase and demand higher standards of living, water consumption also rises. Access to adequate clean water is essential for health, to generate livelihoods, to promote food security and to sustain ecosystems (UNWWD 2003; Komnenic et al. 2009; Cook et al. 2009). The strong link between water provision and poverty alleviation has been highlighted in many studies (Sullivan 2002; Cohen and Sullivan 2010) though the causes of poverty and their relation to water are very complex (Molle and Mollinga 2003; Komnenic et al. 2009; Harrington et al. 2009). As sound water resources management is paramount to governments, river basin authorities and development agencies, an increased understanding of a region's water poverty or prosperity is imperative when targeting strategic measures. Efforts need to recognize and address the pre-conditions and challenges facing different types of households and communities. The poor often have more limited water access and issues prioritized by women (household water collection and privacy in relation to sanitation) are often overlooked or ignored.

To address and combat water problems and disparities, the Water Poverty Index (WPI) was designed to holistically describe the water situation in five main areas: Resources, Access, Capacity, Use and Environment (Sullivan 2002). It has been applied at various scales: national (Lawrence et al. 2002; Komnenic et al. 2009; Cho et al. 2010), river basin (Pérez-Foguet and Giné Garriga 2008; Manandhar et al. 2012; Pandey et al. 2012), regional/district/sub-district (Heidecke 2006; Manandhar et al. 2012) and local (Sullivan et al. 2003; Cullis and O'Regan 2004; Giné Garriga and Pérez-Foguet 2011; Sullivan and Meigh, 2007; Manandhar et al. 2012). Its methodological structure has also been used in a number of WPI based indices e.g. the Climate Vulnerability Index (Sullivan and Meigh 2004), the Livelihood Vulnerability Index (Hahn et al. 2009), the Water, Economy, Investment and Learning Assessment Indicator (Cohen and Sullivan 2010) and the Modified Water Poverty Index (Ty et al. 2010). 
Although earlier water accounting tools mainly addressed availability and quality, the WPI expanded the water management concept to include aspects related to management capacity, equity of access and environmental conditions (Sullivan 2002). The index provides a comprehensive framework that combines various water-related issues that are often treated disparately: agriculture (e.g. irrigation), potable water, health, etc. If based on the prioritized issues of relevant stakeholder groups, it has the potential to be a useful application for assessing the current water situation, setting relevant goals, monitoring progress and serving as a comprehensive water resources framework for more informed and transparent decision making.

\subsection{Indices and Indicators}

Choosing appropriate indicators for an index, should always be done according to relevance not data availability although in practice this is usually not the case (Revenga 2005). Although many indices are used as measures of progress e.g. the Human Development Index and Millennium Development Goals, their inherent disadvantages are well known: their static overview, poor data availability and quality, difficulties in combining highly different issues and loss or distortion of information after aggregation. They are often not transparent and their methods of calculation and assumptions are hidden. For more detail see e.g. Molle and Mollinga 2003; Mayer 2008. Much responsibility thus rests on the user to understand and appropriately use their results.

The WPI was first set up at national scale using available statistical data to describe the existence and magnitude of resources, services and institutions. It was criticized for its weakness in assessing the adaptive capacity of inhabitants (Feitelson and Chenoweth 2002; Molle and Mollinga 2003), the fact that the aggregated components or index hide the actual drivers of water problems (Komnenic et al. 2009; Molle and Mollinga 2003) and that the indicators cannot 
describe the "causes, impact of and remedies to water scarcity and are unlikely to be able to solve such a wide range of problems" (Molle and Mollinga 2003. p. 541).

When applied at community scale, a greater number of "quality-related" indicators e.g. number of students per teacher, students per school and sanitation adequacy were included (Giné and Pérez-Foguet 2005; Cohen and Sullivan 2010). Although difficult to define (Charmes and Wieringa 2003) they increase understanding about what improvements are needed. While quantitative data measure "how much", qualitative data describe "how well" various elements function. Care must however be taken to ensure that the data used to describe them is current and reflects the views of a wide number of stakeholders including the poorest, the least-powerful and both men and women. Challenges still remain to define more pertinent quality indicators.

\subsection{A Participatory WPI}

Participatory methods, although being time consuming to perform, offer great value in eliciting local knowledge to assess the adequacy of resources, services and institutions in meeting local needs (Chambers 1997). Many studies now propose that decisions on how to effectively manage natural resources are best done by local stakeholders who are the direct and ultimate decisionmakers (Kainer et al. 2009). Stakeholder participation has also been acclaimed to boost the critical examination of scientific and technical information, strengthen the search for locally adapted and accepted solutions, and help implement political decisions (Eisenhauer and Nicholson 2005; Blomqvist 2004; Jonsson 2005; Pahl-Wostl 2002; Andersson et al. 2008). Yet participatory methods have also met criticism because although they may be desirable in practice, they are sometimes only idealistic conceptions that do not acknowledge and address the plurality of standpoints, uneven power dynamics, conflicting stakes and distributive inequalities (Cleaver, 1999; van den Hove, 2006; Singleton 2009). Yet it remains important to create forums where 
different stakeholders can interact, share knowledge and develop effective working relations e.g. through common projects (Singleton 2009). Different knowledge sources e.g. from lay people or western science, cover a variety of spatial, temporal, cultural and spiritual spheres and contexts so when combined, knowledge is enhanced (Kainer et al. 2009; Wilk 2009). Numerous participatory learning processes have been used in water management to test, evaluate and develop processrelated factors connected to various decision-support instruments (e.g. Jonsson et al. 2009; Alkan Olsson et al. 2011). These have given valuable insights to the interplay between outside and local knowledge, and how various forms of knowledge can be synthesized into a well-founded water management regime (Jonsson et al. 2005). This however involves fostering a positive interaction between stakeholders and managing different opinions and even conflicts to arrive at beneficial solutions (Tippet et al. 2005). In many instances however these solutions have to be negotiated between groups with different pre-conditions, goals, stakes and levels of influence (van de Hove 2006).

The WPI is based on the premise that it should be developed in a participatory, transparent and inclusive manner with end-users (Sullivan 2002). In Sullivan et al. (2003) participatory consultation was performed with representatives of potential end-users to identify essential issues and test the usefulness of the approach (Sullivan et al. 2003) while in other studies, end-users mainly functioned as data providers (Giné and Pérez-Foguet 2005; Hahn et al. 2009; Cohen and Sullivan 2010). Even if the WPI contains key issues for the chosen stakeholder group, without sufficient consultation with end-users, the results will only reflect the researchers' view (Komnenic et al. 2009). To our understanding, WPI studies to date have not realized the full potential that the index offers for interactive learning and reflection of community views, issues and priorities through the utilization of a more participatory and inclusive process when setting up the index. While WPI design allows differential weighting of the components to reflect 
various stakeholder perceptions or priorities e.g. between different community groups or genders, this has not has been performed in previous studies.

In this study, a Water Prosperity Index $\left(\mathrm{WPI}^{+}\right)$was setup with a number of locally relevant indicators that the communities felt defined their water situation based on different types of data from various sources. While both the WPI and the $\mathrm{WPI}^{+}$describe the local water situation, the $\mathrm{WPI}^{+}$by allotting positive aspects higher scores, does so from the viewpoint of water prosperity rather than poverty. A gender-weighted $\mathrm{WPI}^{+}$was also calculated to illustrate the different priorities of men and women. While it is generally known in many instances that men and women may have different priorities related to water issues, this can be more easily stressed to decisionmakers if highlighted numerically. Moreover, while a diagnosis of water poverty might be appropriate from a top-down perspective, we argue that water prosperity, as a goal to plan and strive for, is a superior concept to depart from in participatory assessments of the water situation.

\section{Aim}

The aim of this paper is to compare differences in approach and results of the community-created $\mathrm{WPI}^{+}$built upon more locally defined indicators with a greater degree of qualitative data and the more expert-dominated WPI (e.g. Sullivan et al. 2003) based primarily on existing quantitative data. Applying the index at a spatial resolution that reveals important socio-economic differences and weighting it according to the different priorities of men and women allowed a more in-depth exploration of the potential usefulness of the index for highlighting spatial, social and gender disparities.

\section{Creating the WPI}




\subsection{The Study Area}

A community of approximately 100 households in Vidisha district, Madhya Pradesh was chosen as our case in consultation with our collaborating NGO. Madhya Pradesh is one of India's least developed states with stark rural-urban disparities. It was ranked 20 of India's 23 states in the latest (data from 2007-2008) Human Development Index (IHDI 2011). The community had recently been actively engaged in participatory projects related to irrigation management (with water user associations) and also hosts a number of active self-help groups, which aim to empower women through micro-credit. Its caste and socio-economic dynamics are similar to many other communities in rural India. A well-established collaboration with the NGO (during the last 10 years) enabled the researchers to gain a more trustful working relationship with the community and increased chances for more long lasting study effects after the conclusion of the project.

Community inhabitants were mainly farmers growing irrigated wheat and rainfed soya bean or wage labourers on local farms. Rainfall in the region was $1100 \mathrm{~mm} / \mathrm{year}$ but farmers are also highly dependent on water from the Samrat Ashok Sagar Irrigation scheme in the Betwa river basin. The community can be distinguished geographically into two sections, the Village and the Hamlet, roughly based on different caste and socio-economic characteristics. The Village contained 43 households of which $50 \%$ belong to scheduled castes. All the households owned land of which $84 \%$ was irrigated. Of the 54 households in the Hamlet, $96 \%$ belonged to scheduled castes. Seventy-two per cent of households owned land of which 59\% was irrigated. There were disparities in irrigation water access between land at the head- and tail-end of the irrigation system, which resulted in large differences in irrigated wheat yields ( 3 respective 0.5 tons/acre). Regarding household water and sanitation, $28 \%$ of Village households had toilets 
compared to $11 \%$ in the Hamlet. Forty-four per cent of Village households and $16 \%$ of Hamlet households had indoor hand pumps.

\subsection{Designing the Participatory Process}

A sufficiently broad range of stakeholders is required to give a participatory process legitimacy as well as to build trust between researchers and stakeholders (Tippet et al. 2005). Effort was put into involving community stakeholders from different socio-economic groups in choice and prioritization of the $\mathrm{WPI}^{+}$indicators, data collection, validation and ranking. During the period 2006-2009, 7 x 2 workshops (6 of these gender separate to allow women to speak more freely) attended by researchers and community members were arranged during four intensive periods of two to three weeks each. Workshops mainly attracted participants from the water user association, which encompassed all landowners (100\% and $72 \%$ of men in the Village and Hamlet respectively), and self-help groups, to which the majority of poor women belong. Women from prosperous households and landless men were targeted separately through individual interviews and surveys.

The first round of two workshops dealt with introducing the WPI concept and performing exercises related to the Resources and Access components. At the second round, the results from Resources and Access were presented and validated or adjusted and exercises were performed for Capacity and Use. At the third round, after previous results were presented, validated or adjusted, the Environmental component was addressed. At the final workshop, attended by community members and local government representatives, the full project results were presented and discussed and water issues prioritized according to gender. Approximately 40 informal interviews with community members, local NGO staff and government officials at the district level were also performed during the intensive field periods. Questionnaires and surveys, participant 
observations, group discussions as well as social visits were also employed as methods of discussing and anchoring different WPI components from the community perspective. Between these intense data-collection periods, the NGO staff continued to visit the village every week to meet, communicate and coordinate work with the community inhabitants and fill data gaps.

Two workshops with researchers, community members and local government officials within the areas of health, water resources and rural development were also held to discuss community perspectives and priorities on water resources with the help of the WPI concept. A meeting was also held at Bhopal, the state capital, with researchers and state-level government officials, to discuss the WPI concept and ideas for its development and potential use in state government departments. As the co-production process was conducted as a research project, no interventions based on the $\mathrm{WPI}^{+}$results, were implemented.

\subsection{Choosing the Indicators}

The indicators used in the WPI ${ }^{+}$(Table 1) are based on Sullivan et al.'s (2003) list for the community WPI. To increase local relevance, the researchers and community members jointly chose, created and/or altered indicators to reflect local perceptions of water-related issues. The complete list is available in Table 1 . The added community-based indicators describe the adequacy of resources and services (e.g. of precipitation, schooling, sanitation) and access to household water or sanitation (the number of household hand pumps and indoor toilets). Much effort was put into designing indicators that better describe community capacity (e.g. selfconfidence and problem-solving abilities). These were gauged by quantifying individual participation in a variety of related activities (Jonsson and Wilk, accepted to Society and Natural Resources). Some community WPI indicators were also eliminated or altered. Time for water collection, including waiting was eliminated because community women do not queue at hand 
pumps but rather postpone water collection until the pumps are free. Instead indicators for the average distance to the two closest hand pumps and the number of households per public hand pump were added. Water use per capita was standardized against recommended daily amounts.

Indicators, within each component, were grouped into two to three identified sub-components that correspond to major water issues (see Table 1). For Resource, they were rainfall, water quality and resources development, for Access, household water, sanitation and irrigation, for Capacity, health and wealth, institutional capacity and systems for learning, for Use, household and irrigation and for Environment, natural resources, pollution and erosion and salinization. Each sub-component (i.e. issue) was thus given an equal weighting within the components in order to reduce sensitivity from an unequal number of indicators.

\subsection{Quantifying and Standardizing the Indicators}

Four different types of data were used to quantify the indicators (Table 1). The first was quantitative data at district level from the Madhya Pradesh Human Development Report (2002) (red text). The second was quantitative data from the Rural Development Office (2004) updated by field surveys and local knowledge that was spatially linked to different community areas (green text). The third was qualitative and quantitative data from interviews, PRA exercises, map drawing, participant observations, group discussions and household visits (blue text; italics and normal text respectively). The qualitative indicators were rated on a scale of 1 to 5 corresponding to Very Bad, Bad, OK, Good and Very Good, separately for the Village and Hamlet if possible, which were then adjusted to the $\mathrm{WPI}^{+}$scale $(10$ - 90). The fourth was qualitative data from a participatory community assessment where the community allotted values (from 1 to 5) to 15 $\mathrm{WPI}^{+}$indicators, three for each component (see Jonsson and Wilk, accepted) (orange text; italics). 
If higher numbers corresponded to negative outcomes, they were inverted. Values that were not expressed in per cent (where 0 represented the worst situation and 100 the optimal) were standardized against values in other districts of Madhya Pradesh or against the worst or optimal community situation according to: $\mathrm{x}_{\mathrm{i}}-\mathrm{x}_{\min } / \mathrm{x}_{\max }-\mathrm{x}_{\min }$.

Table 1. List of indicators for the Community WPI and $\mathrm{WPI}^{+}$, and the Village and Hamlet $\mathrm{WPI}^{+}$. $\mathrm{HH}=$ household; WUA= water users association. The various data sources are indicated by: Red text: quantitative data from the Madhya Pradesh Human Development Report (2002) based on Census of India (2001); Green text: quantitative data from the Rural Development Office (2004) updated with field surveys; Blue text: qualitative (shown in italics) and quantitative data from interviews, PRA exercises, map drawing, participant observations, group discussions and household visits; Orange text: qualitative (shown in italics) data from a participatory assessment of 15 indicators performed at a workshop attending with male and female community members.

\begin{tabular}{|c|c|c|c|c|}
\hline Indicators & $\begin{array}{l}\text { Community } \\
\text { WPI }\end{array}$ & $\begin{array}{l}\text { Community } \\
\text { WPI }^{+}\end{array}$ & $\begin{array}{l}\text { Village } \\
\text { WPI }^{+}\end{array}$ & $\begin{array}{l}\text { Hamlet } \\
\text { WPI }^{+}\end{array}$ \\
\hline \multicolumn{5}{|l|}{ Resources } \\
\hline \multicolumn{5}{|l|}{ Rainfall } \\
\hline Annual Rainfalli & 53 & 53 & 53 & 53 \\
\hline Variability of Rainfall ${ }^{\mathrm{ii}}$ & 77 & 77 & 77 & 77 \\
\hline Adequacy of Rainfall & 50 & 50 & 50 & 50 \\
\hline Adequacy of Rainfall & & 60 & 60 & 60 \\
\hline Mean & 60 & 60 & 60 & 60 \\
\hline \multicolumn{5}{|l|}{ Water Quality } \\
\hline Water quality $^{\text {iv }}$ & 100 & 100 & 100 & 100 \\
\hline Water quality & & 60 & 60 & 60 \\
\hline Mean & 100 & 80 & 80 & 80 \\
\hline \multicolumn{5}{|l|}{ Resources Development } \\
\hline Groundwater Development ${ }^{\mathrm{v}}$ & 93 & 96 & 96 & 100 \\
\hline Surface water availability ${ }^{\mathrm{vi}}$ & 72 & 72 & 84 & 59 \\
\hline Adequacy of Irrigation Water Supply ${ }^{\mathrm{vii}}$ & 50 & 50 & 50 & 50 \\
\hline Adequacy of Irrigation Water Supply & & 70 & 70 & 70 \\
\hline Mean & 72 & 72 & 75 & 70 \\
\hline TOTAL Resources & 77 & 71 & 72 & 70 \\
\hline
\end{tabular}

\section{Access}


Household Water

Access to safe water $(\%)^{\text {viii }}$

Adequacy of water access

100

Adequacy of water access

$\begin{array}{llll} & 50 & 60 & 40 \\ & 40 & 40 & 40 \\ 25 & 63 & 79 & 61 \\ & 25 & 44 & 9 \\ 63 & 67 & 81 & 51 \\ & 49 & 61 & 40 \\ 39 & 20 & 28 & 11 \\ & 20 & 30 & 10 \\ 39 & 10 & 10 & 10 \\ & 17 & 23 & 10\end{array}$

Distance to collect water (m)

70

HHs per public $\mathrm{HP}^{\mathrm{xi}}$

Mean

$\begin{array}{lll}70 & 80 & 60\end{array}$

$\begin{array}{llll}25 & 92 & 95 & 77\end{array}$

Access to irrigation ${ }^{\mathrm{xii}}$

70

Access to irrigation

$25 \quad 77$

70

70

Mean

42

48

82
55

69

TOTAL Access

$\begin{array}{llll}48 & 48 & 48 & 48 \\ 58 & & & \\ & 85 & 100 & 72 \\ & 30 & 30 & 30 \\ 53 & 54 & 59 & 50 \\ & & & \\ & 75 & 78 \text { (men) } & 72 \text { (women) } \\ 100 & 73 & 73 & 73 \\ & 100 & 100 & 100 \\ 100 & 50 & 40 & 60 \\ & 70 & 70 & 70 \\ 57 & 73 & 70 & 75 \\ 92 & & & \\ & 57 & 57 & 57 \\ 75 & 100 & 100 & 100 \\ \mathbf{7 6} & 50 & 50 & 50 \\ & 69 & 69 & 69 \\ & \mathbf{6 5} & \mathbf{6 6} & \mathbf{6 5}\end{array}$

Capacity

Health and Wealth

Child mortality (per 1000) ${ }^{x i i i}$

Ownership of durable items ${ }^{\text {xiv }}$

Ownership of land (\%)

Adequacy of health care

Mean

Institutional Capacity

Self-confidence (\% points)

Problem-solving (\% points)

Membership in WUAs (\%)

Membership in SHGs (\%)

Social Capital

Mean

55

40

Systems for Learning

Rural literacy (\%)

Primary school enrolment (\%)

Adequacy of education

Mean

TOTAL Capacity

Use

Household Water

Water use (lpcd) ${ }^{\mathrm{xv}}$

25

Water use efficiency

$25 \quad 17$

17

100

Water use and Efficiency

Reports of conflict ${ }^{\mathrm{xvi}}$

Mean

25

90

70

69

17

17

rrigation Water

Agricultural use (\%)

86

Reports of conflict

Mean

86

86

10

48

100

100

90

70

90

70

69

69

6

95

77

6

10

53

44 
TOTAL Use

\section{Environment}

Natural Resources

Use of Vegetation ${ }^{\mathrm{x}}$

Value of wildlife and vegetation

Mean

Pollution

Pollution

Mean

Erosion and Salinization

Land with erosion (\%)

Erosion and salinization

Mean

TOTAL Environment
56

100

100

70

85

85

92

69
70

59

100

50

75

$70 \quad 70$

85

70

78

74

63
61

57

TOTAL

$\begin{array}{rr}85 & 85 \\ 70 & 70 \\ 78 & 78 \\ \mathbf{7 4} & \mathbf{7 4}\end{array}$

\subsection{Creating a Spatial WPI ${ }^{+}$}

WPI results can be spatially displayed in a Geographic Information System (GIS) (Sullivan 2002)

which is a computer system for the input, management, analysis and mapping of digital spatial information. Because of the highly visual nature of spatial data, GIS enables new forms of communication e.g. within or across groups from different research disciplines and communities (Goodchild 2000). In environments where people are not accustomed to maps, digital photographs and/or computers, creating a GIS database is especially challenging. If stakeholders are closely involved in the creation of maps and databases, they are better able to link these to their environment and broaden their views to other scales e.g. river basin (Tippet et al. 2005) and validate them as representing their reality. Building databases together with stakeholders also increases trust between participants (Barraqué et al. 2004) and employing local inhabitants as coresearchers, has the potential to increase mutual understanding of alternative realities (Garnett el al. 2009). 
Creating locally representative maps often requires a number of steps e.g. transferring local drawings to digital maps, negotiating and making corrections, additions and simplifications on route. In our process, after the inhabitants drew their community and fields on paper, the maps were entered into GIS with the help of GPS coordinates, overlaid with photographs of landmarks e.g. temples, school and kiosk (Fig. 1) and presented back to the community for correction or validation. Inhabitants also ranked different areas of the community according to access to sanitation (Fig. 2) and irrigation water (Fig. 3). The hand-drawn sanitation map was drawn in GIS (Fig. 4) and the irrigation map was overlaid with a digital field map (Fig. 5).

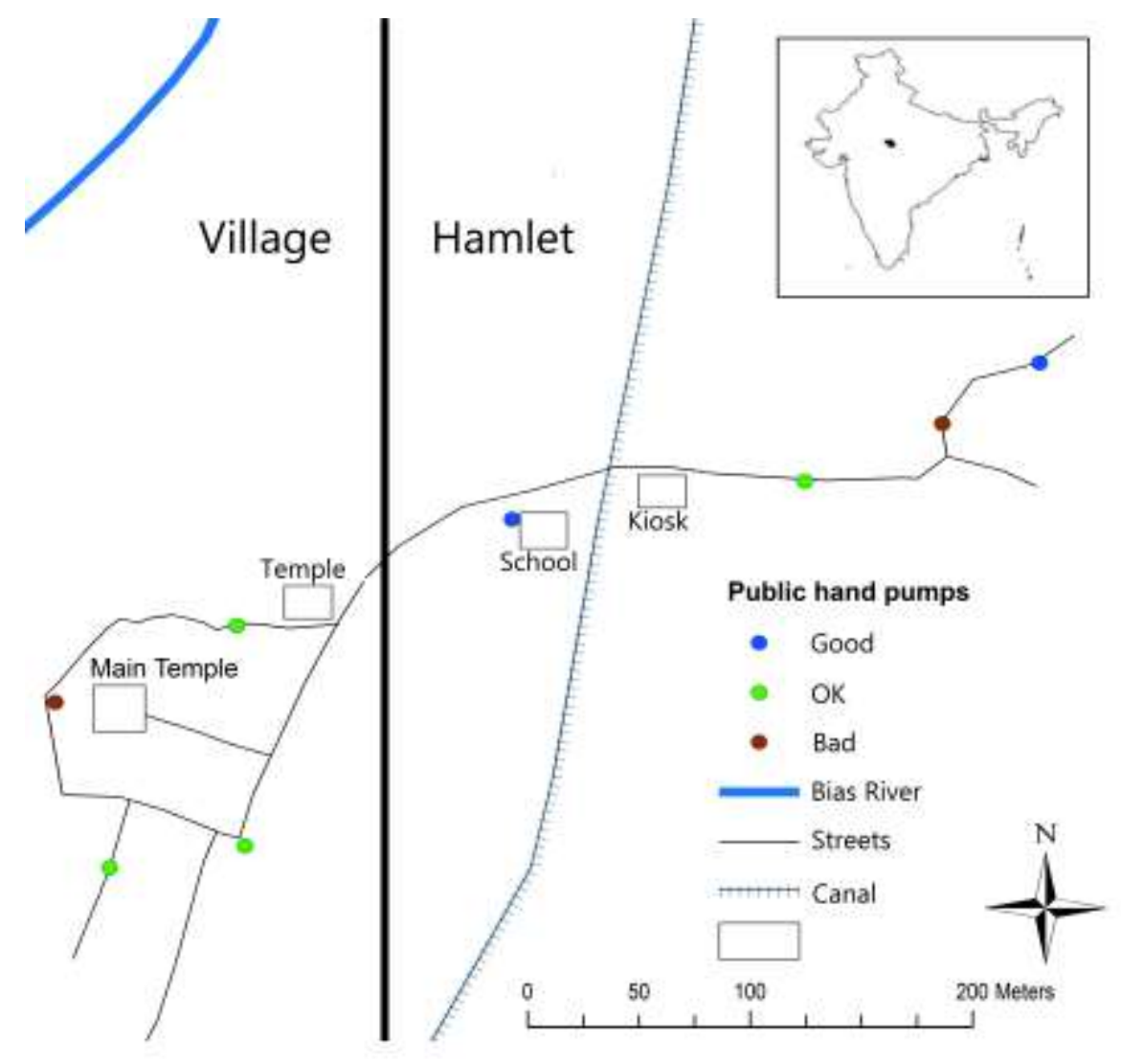

Fig 1. Community map showing division into Village and Hamlet, important landmarks and location and quality ranking of public hand pumps 


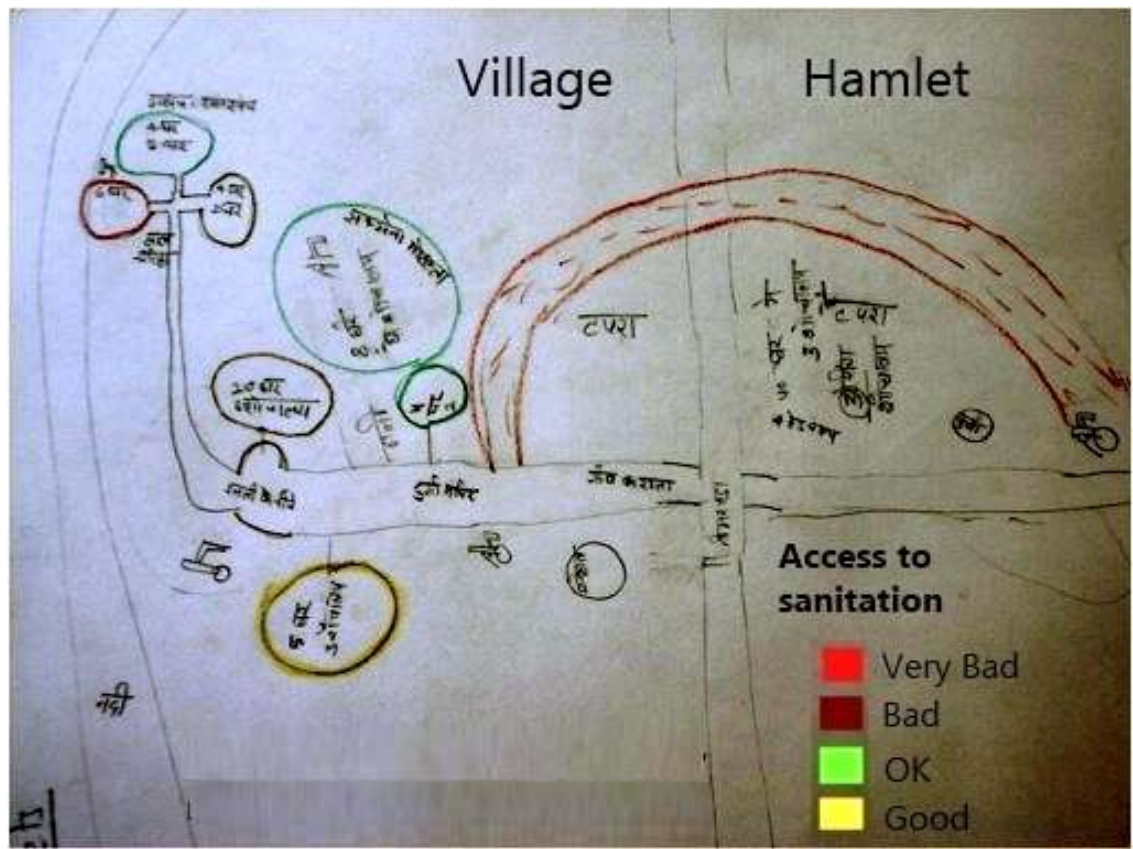

Fig. 2 Hand-drawn community map showing access to sanitation. Very $\mathrm{Bad}=<20-40 \%$; OK=41$60 \% ;$ Good $=61-100 \%$. 


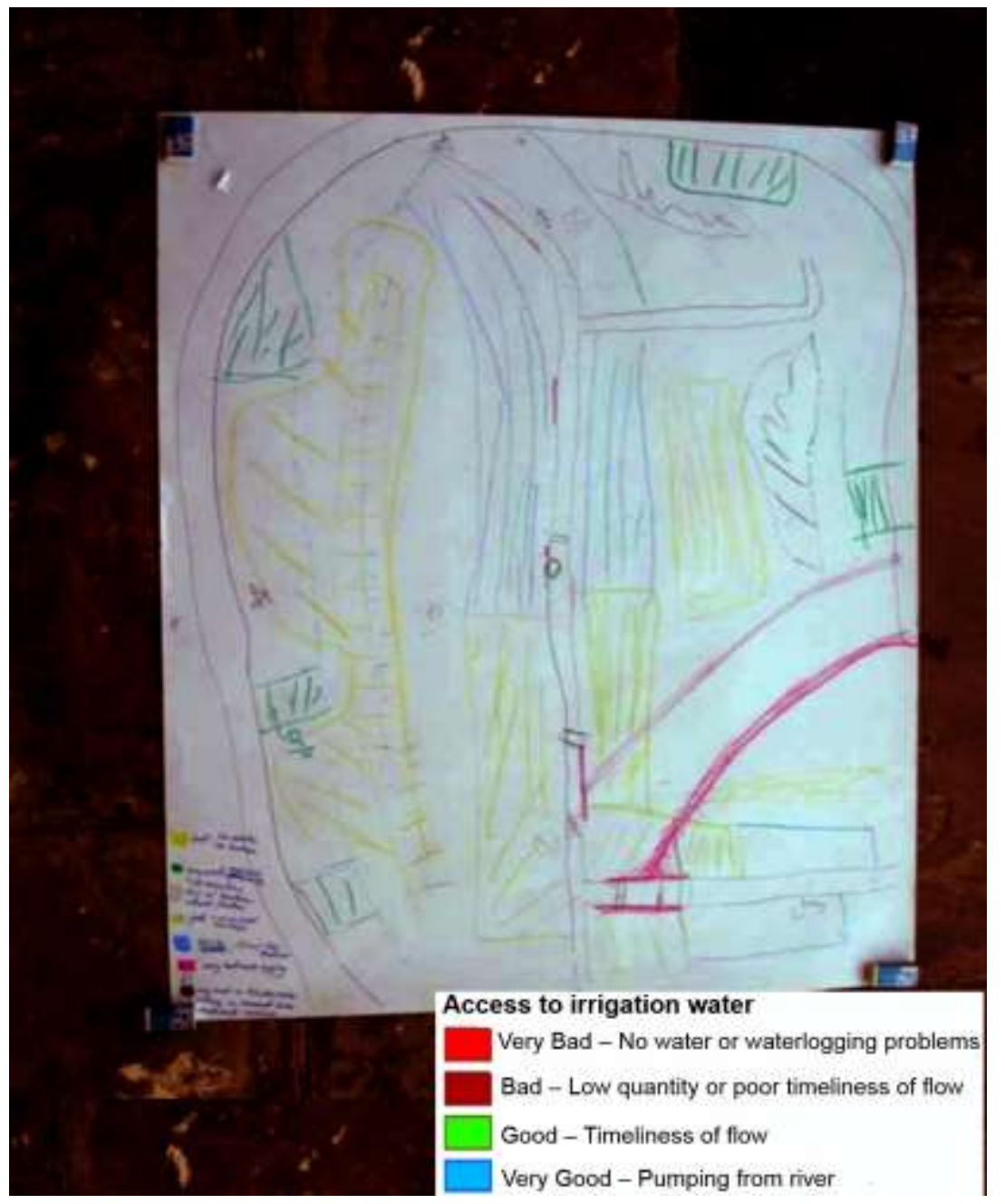

Fig. 3 Hand-drawn community map showing access to irrigation water 


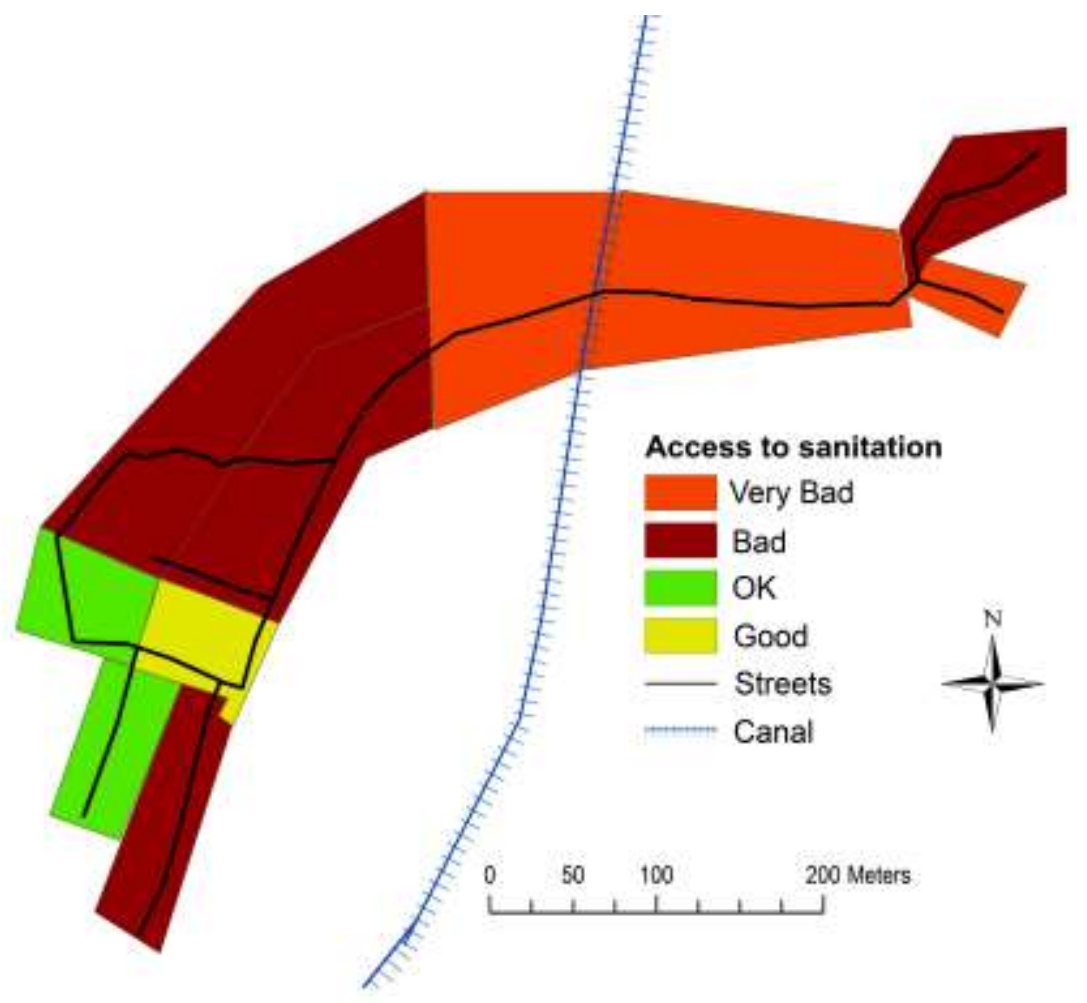

Fig. 4 Digital map showing access to sanitation in the Village and Hamlet. Very Bad 0>20\% indoor toilets; $\mathrm{Bad}=20-40 \% ; \mathrm{OK}=41-60 \%$; Good=61-100\% 


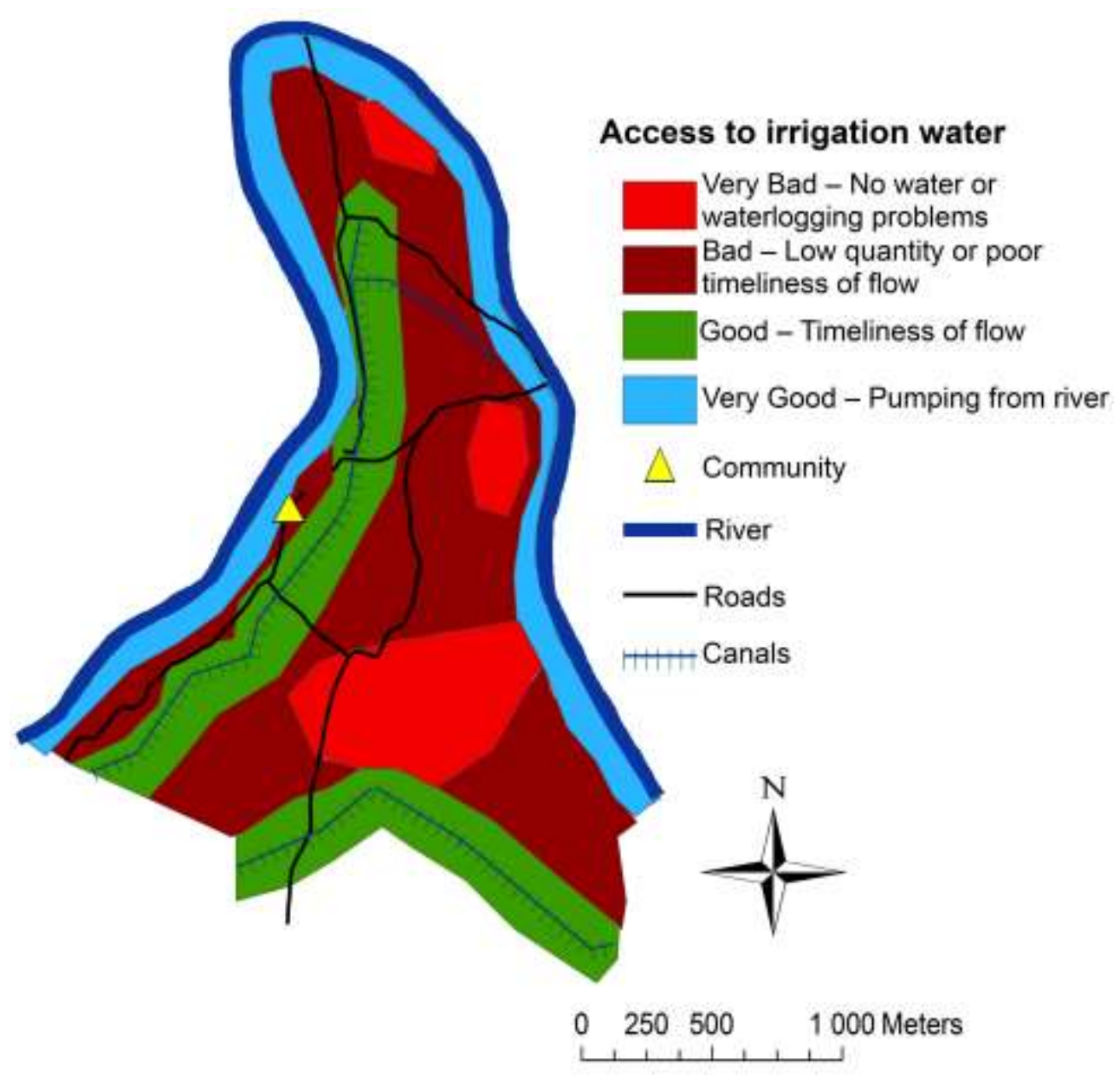

Fig. 5 Digital map showing access to irrigation water for the community fields

A community co-researcher was employed to spatially link data from the Rural Development Office to each household and collect additional information e.g. caste membership, existence of indoor toilets and hand pumps. Not all data could be linked to the spatial objects of Community, Village and Hamlet as it was difficult to link fields to households, as many of the more prosperous landowners resided in the district capital. Local knowledge and land-ownership records however confirmed that the more prosperous Village households generally own land at the head-end of the irrigation system, which receives more timely distribution of water. 


\subsection{Weighting and Calculating the WPI and $\mathrm{WPI}^{+}$}

A Community WPI was calculated primarily based on available quantitative data. A WPI ${ }^{+}$was calculated for Community, Village and Hamlet. The mean was first calculated for each subcomponent, after which the mean was taken of these scores to calculate the components. Finally, the mean was taken of the five component scores, with equal weighting. Equal weighting was used instead of other methods such as weighting based on multivariate analysis (see Giné and Pérez-Foguet, 2010) to make the index construction as simple as possible for the sake of community transparency. The values of the WPI were inverted to make comparison with the $\mathrm{WPI}^{+}$possible. A weighting based on gender-prioritized components was also performed for the Community $\mathrm{WPI}^{+}$.

\section{Results}

\subsection{Community WPI and WPI ${ }^{+}$}

The $\mathrm{WPI}^{+}$was based on 43 indicators and the WPI on 22. While WPI and $\mathrm{WPI}^{+}$index scores were similar (69 and 63) a closer look at the components, sub-components and indicators revealed major differences. The $\mathrm{WPI}^{+}$showed lower values for Resources, Capacity and Environment and higher for Access and Use (Fig. 6) .The differences in values for the three subcomponents were greatest for Access. While Access to household water and Access to sanitation were higher in the WPI than in the $\mathrm{WPI}^{+}$(63 compared to 49 and 39 vs. 17), Access to irrigation was much lower (25 compared to 77). 

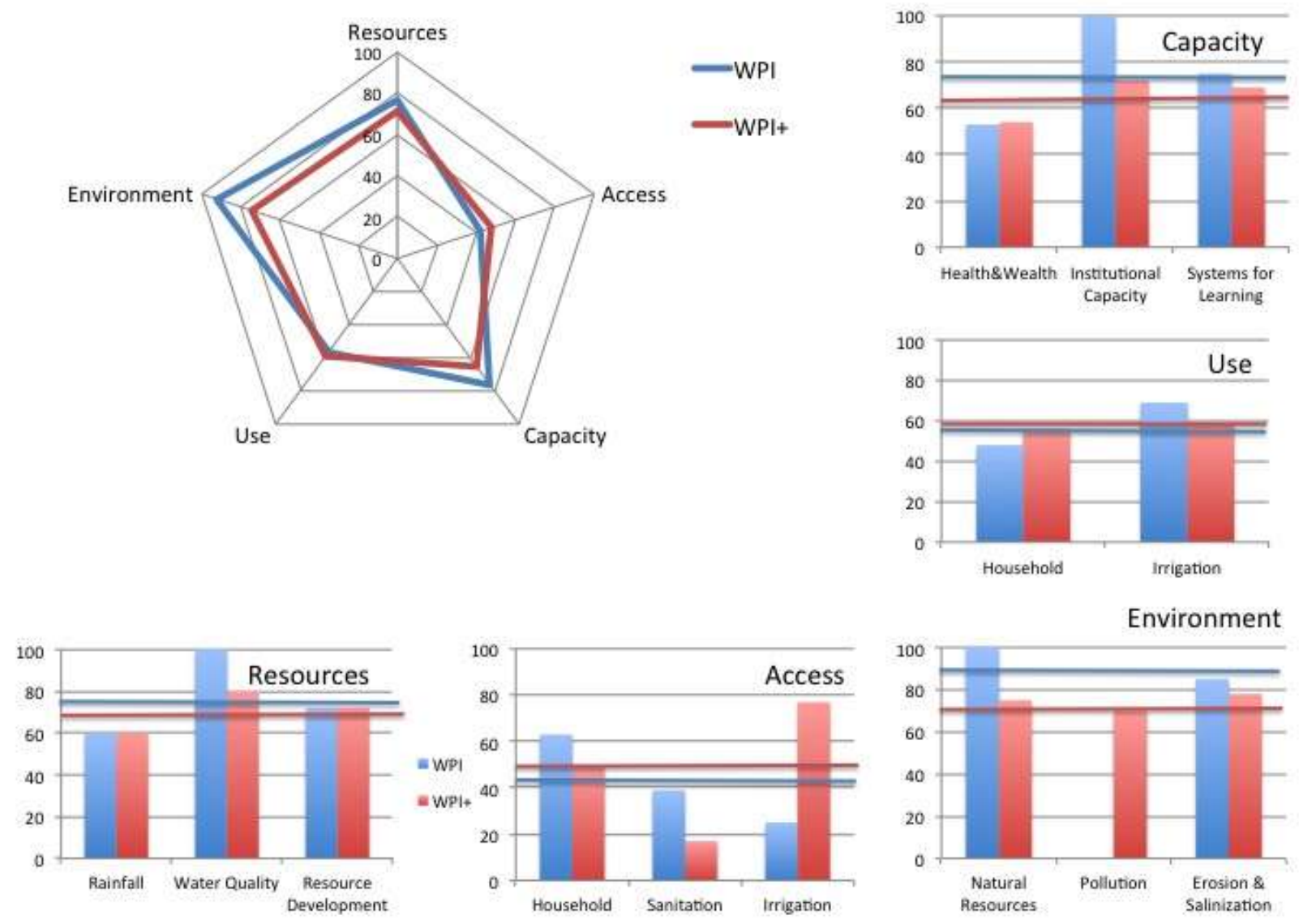

Fig. 6 Pentagram of the WPI (blue line) and $\mathrm{WPI}^{+}$(red line) for the community and bar charts for each component with the values for each sub-group and lines showing the WPI and $\mathrm{WPI}^{+}$totals

\subsection{Village, Hamlet and Gender-based WPI ${ }^{+}$}

When calculating the $\mathrm{WPI}^{+}$for the Village and Hamlet respectively, the only notable difference in the aggregated $\mathrm{WPI}^{+}$was for Access (55 in Village and 40 in Hamlet), but again differences were greater at sub-component level (see Fig. 7). The gender-based $\mathrm{WPI}^{+}$was almost identical for men (61) and women (60) (Table 2). Although both ranked Access as the most important component (38\% of men and $33 \%$ of women), the percentage of women that ranked Capacity highest was 
three times higher than that of men (24\% and $8 \%)$. The three most important components for women were Access, Capacity and Environment and for men Access, Environment and Use.
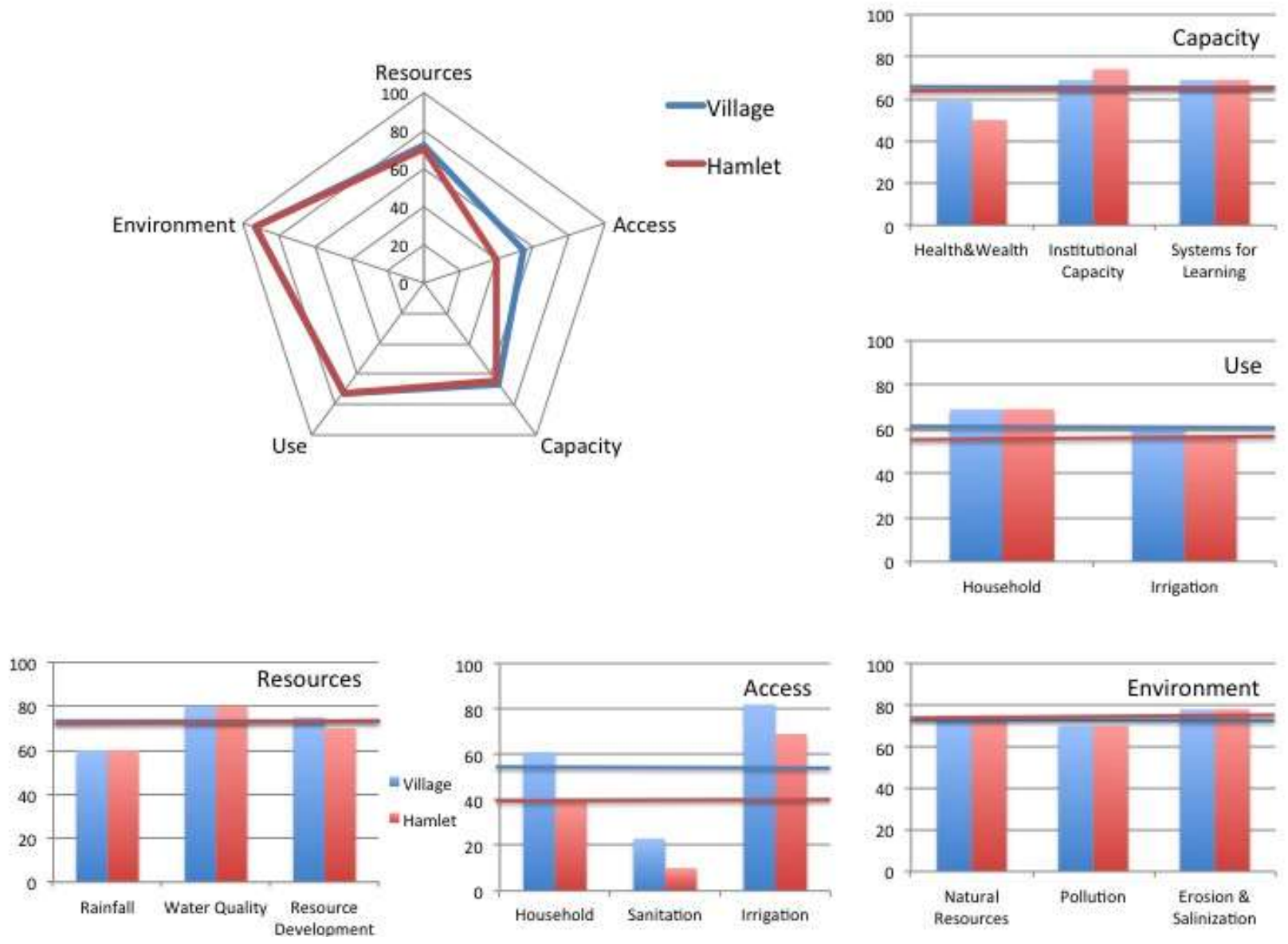

Fig. 7 Pentagram of the $\mathrm{WPI}^{+}$for Village (blue line) and Hamlet (red line) and bar charts for each component with the results for each sub-group and lines showing the WPI and $\mathrm{WPI}^{+}$totals 
Table 2. Weightings of the $\mathrm{WPI}^{+}$components for men and women (\%) plus the total $\mathrm{WPI}^{+}$scores

\begin{tabular}{lcc}
\hline & Men & Women \\
\hline Resources & 16,7 & 11,1 \\
Access & 37,5 & 33,3 \\
Capacity & 8,3 & 24,1 \\
Use & 12,5 & 9,3 \\
Environment & 25,0 & 22,2 \\
\hline WPI $^{+}$ & 61 & 60 \\
\hline
\end{tabular}

\section{Discussion}

\subsection{The WPI and $\mathrm{WPI}^{+}$}

The main difference between the Community WPI and $\mathrm{WPI}^{+}$is not reflected in the index scores but rather in the construction process and in the indicators and types of data that were used. The WPI is based on half the number of indicators as the $\mathrm{WPI}^{+}$and almost half of the sub-component scores are based on one indicator. While an index with fewer indicators is more manageable and useful for comparisons between communities and regions, it also makes the resulting index more sensitive to erroneous, non-current or non-representative data. The $\mathrm{WPI}^{+}$contains a larger number of diverse indicators with different types of community data thus enabling it to better describe how well various water-related issues were functioning in the community (Table 1). We consider the $\mathrm{WPI}^{+}$to have greater community relevance because of the participatory input in indicator selection and data validation by a large range of inhabitants including village leaders, which to our knowledge was not as rigorously performed in other community WPI studies.

To increase the validity and success of a participatory process, it must be well-embedded within the local institutional setting and the choice and assessments of methods and goals undertaken in a forum that involves as many community stakeholder groups as possible (men and women; poor and prosperous; landowners and landless, etc.) with special attention to inclusion of 
marginal groups. As participation is voluntary and gatekeeper effects are often strong, ensuring the representativeness of participants is a difficult challenge. Embedding the $\mathrm{WPI}^{+}$setup process in existing institutional community structures (water user associations and self-help groups) and also dedicating much time and effort into complementing it with input from inhabitants outside these groups, broadened the community perspective of the $\mathrm{WPI}^{+}$. Meetings between community members and local government officials also allowed dialogue with and input from decisionmakers.

\subsection{Levels of Numerical Aggregation}

Numerical aggregation allows patterns to emerge but it can also mask important disparities and issues. As other papers have pointed out (e.g. Molle and Mollinga 2003, Komnenic et al. 2009) similarities and differences between index scores occur for a number of reasons. While Resources and Access only differed by 6 points between the WPI and $\mathrm{WPI}^{+}$, for Resources, the similarity was because seven of ten indicators were common to both indices (six with identical data) (see Table 1). For Access, only three of 12 indicators were the same (one with identical data) but the great number of differences disappeared when the mean was taken. Although the indicators scores between the two indices were very different the resulting component mean was surprisingly similar.

Even at the lower level of aggregation of the sub-components, the results show that much telling information, disparities and issues remain hidden. For example, the relatively high score for systems for learning ( 69 for the Community $\mathrm{WPI}^{+}$) is in fact due to a combination of the poor rates for adequacy of education (50) and rural literacy (57) and the very high primary school enrolment $(100 \%)$ despite that in reality truancy is rampant (see Table 1). Another example is irrigation water use, where the low score from a high frequency of conflicts (10) is raised to 48 by 
the high percentage of irrigated to total land (86), although the tail-end areas remain dry in poor rainfall years. These examples illustrate how the poor performance in some indicators can be offset and thus disguised by others with higher values.

While the WPI structure with its aggregated totals can mask pivotal issues, what it offers is a framework on which to organize water related data. It is however essential to also show what the totals are based upon, the type, source and collection methods of data as well as what the indicators describe (e.g. in a table such as Table 1). At the other end of the spectrum, while indicators provide more detailed information, even they can give a fragmented and sometimes faulty picture and transparency is also essential here to avoid misconceptions. There is a trade off between the structured information in the $\mathrm{WPI}^{+}$that can mask disparities and the great detail of the indicators themselves that can however fail to capture and relay the bigger picture.

\subsection{Socio-economic and Gender Differences}

The Village $\mathrm{WPI}^{+}$showed higher Access scores than for the Hamlet (Fig. 7) indicating an important area of disparity between more and less prosperous households in the areas of irrigation, household water and sanitation. Great differences are apparent in the indicators that describe percentage of household hand pumps and sanitation facilities as well as access to irrigation water. Both areas showed similar Capacity scores but this does not necessarily reflect similar pre-conditions but rather that the data for most indicators (9 of 11) were the same (Table 1). The Use score for household water was identical for both areas reflecting the fact that, although households with indoor hand pumps had more ready access to water, they however still used similar daily amounts as families relying on outdoor hand pumps. One explanation is that all households are very water efficient regardless of the proximity of their water source.

The gender weighted $\mathrm{WPI}^{+}$(Table 2) illustrated how the index can be used to show differences 
in perceptions and priorities between groups, in this case between men and women. Both men and women ranked Access issues as most important although for different reasons. In the WPI workshops men strongly focused on discussions of irrigation water while women directed their attention to household water collection and sanitation issues. Capacity was ranked much higher by women than men which could be because most of the women that attended the final workshop and participated in the ranking exercise belonged to well-functioning self-help groups that were considered strong forums for capacity building. The water users association, the only community institution with male members, had no pronounced aim of building capacity. This simple weighting therefore pinpoints clear gender differences that by acknowledging and highlighting them can increase dialogue and understanding between different groups as well as direct attention and remedial actions where they are most needed.

\subsection{The Usefulness of the $\mathrm{WPI}^{+}$}

Despite the many limitations of indices, we however judge the $\mathrm{WPI}^{+}$to be a useful framework for working with water issues because of its holistic structure on which discussions, priorities and more detailed work can be based. While caution must be taken when setting up a WPI based index, to avoid subjectivity, outsider world-views and manipulation by powerful actors (Molle and Mollinga 2003) this is equally true for all studies and methodologies. While participatory methods have their drawbacks, if serious efforts are taken to acknowledge, address and adequately account for these, they can still be successfully used to foster transparent and flexible community processes. The inclusion of more qualitative and stakeholder chosen indicators in the $\mathrm{WPI}^{+}$make its results more "bottom-up" than less participatory created indices. However the index and component totals can only provide an overview, and as such, they cannot offer analyses of causes, impacts and complex interrelationships. Any remedial actions or interventions must be 
based on more in-depth studies.

The organization of government departments is often incongruent with water management paradigms building on a systems approach (Shah and van Koppen 2006). They are often highly sectorised with strict administrative boundaries between departments dealing with water related issues i.e. health, water provision, irrigation and environment. For example, while many communities advocate the drilling of more bore holes, in many areas of Madhya Pradesh increased groundwater use has depleted local reserves so that even with a greater number of hand pumps, total water flow would still be reduced. As issues such as these usually fall under the responsibilities of different government departments, a comprehensive view of water issues, which the $\mathrm{WPI}^{+}$could provide, is lacking so many solutions remain disjointed and unsustainable.

The $\mathrm{WPI}^{+}$also has potential for NGOs who work with water related issues. The staff in our collaborative NGO found the holistic $\mathrm{WPI}^{+}$framework to be a good bridge between work with the (male) water users association and (female) self-help groups. Study results with maps and related databases were found beneficial for increasing contact and dialogue between community members, NGO workers and local and state government representatives (Wilk and Jonsson 2008).

While an important component of this study was to include community-based indicators, this excludes comparability. If the $\mathrm{WPI}^{+}$is to be applied in a number of communities, communitybased indicators, chosen and standardized after a rigorous pilot study in the area, would increase relevance and meet the objective of comparability. If instead the $\mathrm{WPI}^{+}$is primarily for the use of the community itself, more locally contextual indicators and data sources would be more appropriate.

\section{Conclusions and Recommendations}


The $\mathrm{WPI}^{+}$created in this study was found to be a useful framework for structuring and describing water issues for the participating community and collaborating NGO. The community $\mathrm{WPI}^{+}$illustrated with greater clarity the types of indicators, data and data collection prioritized by community inhabitants. These aspects stressed the adequacy of services and resources with focus on those that describe water access and individual capacity for water management (for more detail see Jonsson and Wilk, accepted). Dividing the community into different socio-economic areas, the Village and Hamlet, also illustrated that even in relatively small communities important distinctions in water conditions can exist that can be easily overlooked if the community is considered as one unit. The gender-weighted $\mathrm{WPI}^{+}$also highlighted differences in a numerical format that decision-makers might more easily react to.

The greatest difference between the WPI and $\mathrm{WPI}^{+}$was not found in the numerical results but rather that it was more heavily based on community-identified indicators and that its methods, data sources and results were transparent and locally validated. Sullivan et al. (2003, p. 198) stated that usage of the WPI could result in "better targeted implementation in the water sector and more efficient use of development budgets, as poor people would be empowered to assess their own water stress, and promote the growth of human and social capital". While they suggested participation in data collection e.g. through national surveys and at schools, we advocate it throughout the entire $\mathrm{WPI}^{+}$setup process to encourage knowledge exchange, interest and commitment to addressing local water issues. A greater degree of stakeholder inclusion invariability has high costs in terms of time and resources (Wilk and Jonsson 2008). Participatory processes are easier to organize at community scale and difficulties multiply exponentially at district, river basin and national level because of the increased complexity, problems of representivity and higher transaction costs. Qualitative data is also time consuming to gather while quantitative data is often more readily available and more conducive to comparability. Yet 
without qualitative data it is difficult to describe the forces that drive (and hinder) effective water resources management. The $\mathrm{WPI}^{+}$would benefit from further development of community chosen indicators e.g. within the Capacity and Environment components. Time and attention must also be given to ensure that chosen indicators and data can reflect any disparities between different socio-economic groups, geographical areas or according to gender. The $\mathrm{WPI}^{+}$calculated at Community, Village and Hamlet scale, illustrated that an index used at higher resolutions and weighted according to the perceptions of different groups, can reveal important differences even in a small community.

Aggregated scores can hide a multitude of interesting aspects so transparency about index construction is essential. The values of sub-components and indicators should be presented along with the aggregated $\mathrm{WPI}^{+}$scores and pentagrams to provide a truer picture of what the real water issues are and where improvements need to be made. Although the relationship between water and poverty is not a direct one, the provision and management of water resources is essential to promote sustainable livelihoods, good health and well-being. This work illustrates how a Water Prosperity Index could be a more grounded and relevant water management tool that better represents local viewpoints and priorities when set-up within an inclusionary and transparent participatory process based on a local institutional framework.

Acknowledgements This work was supported by the Swedish International Development Cooperation Agency (SIDA). We would like to thank the community members who participated in this project and employees of our collaborative NGO for their valuable time and knowledge. We also thank Mattias Hjerpe and Kalash Jatavfor valuable work in mapping, indicator development and data collection.

\section{References}


Alkan Olsson J, Jonsson AC, Andersson L, Arheimer B (2011) A model-supported participatory process for nutrient management: a socio-legal analysis of a bottom-up implementation of the EU Water Framework Directive. Int J of Agr Sust 9(2):379-389

Andersson L, Alkan Olsson J, Arheimer B, Jonsson, AC (2008) Use of participatory scenario modelling as platforms in stakeholder dialogues. Water SA 34:439-447

Barraqué B, Le Bourhis JP, Maurel P, Raymond R (2004) Public participation in the Dordogne River Basin, Case study report produced under Work Package 5 of the HarmoniCOP project. LATTS-CNRS, Paris, Sorbonne University, SEMAGREF

Blomqvist A (2004) How can stakeholder participation improve European watershed management? The Water Framework Directive, watercourse groups and Swedish contributions to Baltic Sea eutrophication. Water Policy 6:39-52

Chambers R (1997) Whose Reality Counts? Putting the first last, Intermediate Technology Publications, London

Charmes J and Wieringa S (2003) Measuring women's empowerment: an assessment of the Gender-Related Developed Index and the Gender Empowermenet Measure J of Hum Dev 4(3): 419-435

Cho DL, Ogwang T, Opio C (2010) Simplifying the Water Poverty Index. Soc Indic Res 95:257-267 doi:

\subsection{7/s11205-009-9501-2.}

Cleaver F (1999) Paradoxes of participation: questioning participatory approaches to development. J of Int Dev 11(4):597-612

Cohen A, Sullivan, CA (2010) Water and poverty in rural China: Developing an instrument to assess the multiple dimensions of water and poverty. Ecol Econ 69:999-1009

Cook SE, Fisher M, Andersson MS, Rubiano J, Giordano M (2009) Water, food and livelihoods in river basins. Water Int34(1):13-29

Cullis J, O'Regan D (2004) Targeting the water-poor through water poverty mapping, Water Policy 6:397411 
Eisenhauer BW, Nicholson B (2005) Using stakeholders' views: a social science methodology for the inclusive design of environmental communications. Appl Environ Educ and Commun 4:19-30

Feitelson E, Chenoweth J (2002) Water poverty: towards a meaningful indicator. Water Policy 4:263-281 Garnett ST, Crowley GM, Hunter-Xenie H, Kozanayl W, Sithole B, Palmer C, Southgate R, Zander KK (2009) Transforming knowledge transfer through empowering and paying community researchers. Biotropica 41(5):571-577

Giné R, Pérez-Foguet A (2005) The Water Poverty Index: Assessing water scarcity at different scales, II Congrés UPC Sostenible 2015. http://upcommons.upc.edu/revistes/bitstream/2099/8123/1/11_Ricard_Gine.pdf. Retrieved on July 22, 2010."

Giné R, Pérez-Foguet A (2010) Improved Method to Calculate a Water Poverty Index at Local Scale. J Environ Eng 136(11):1287-1298”

Giné R, Pérez-Foguet A (2011) Application of a revised Water Poverty Index to target the water poor. Water Sci and Tech 63(6):1099-1110

Goodchild,MF (2000) Communicating geographic information in a digital age. Ann. Am. Geographers 90(2):344-355

Hahn MB, Riederer AM, Foster SO (2009) The Livelihood Vulnerability Index: a pragmatic approach to assessing risks from climate variability and change - a case study in Mozambique. Global Environ Change 19:74-88

Harrington L, Cook SE, Lemoalle J, Kirby M, Taylor C, Woolley J (2009) Cross-basin comparisons of water use, water scarcity and their impact on livelihoods: present and future. Water Int 34(1):144-154 Heidecke C (2006) Development and Evaluation of a Regional Water Poverty Index for Benin. EPT Discussion Paper, No. 145, International Food Policy Research Institute, Washington, DC Jonsson A (2005) Public participation in water resources management: stakeholder voices on degree, scale, potential, and methods in future water management AMBIO 7:495-500

Jonsson A, Lövbrand E, Andersson L (2009) Participatory research in theory and practice: why, how and 
when? In: E. Lövbrand, B.-O. Linnér, and M. Ostwald, eds. Climate science and policy research: conceptual and methodological challenges, Linköping: Centre for Climate Policy and Research Report 09:03

Jonsson A, Wilk J Opening up" the Water Poverty Index - exploring water access and management capacity at the village level. Accepted by Society and Natural Resources.

Kainer KA, Digiano M, Duchelle MA, Wadr LHO, Wadt E, Dain JL (2009) Partnering for greater success: Local stakeholders and research in tropical biology and conservation. Biotrop 41:555-562

Komnenic V, Ahlers R, van der Zaag P (2009) Assessing the usefulness of the water poverty index by applying it to a special case: Can one be water poor with high levels of access? Phys and Chem of the Earth (34):219-224

Lawrence P, Meigh J, Sullivan C (2002) The Water Poverty Index: An international comparison. Keele Economics Research Papers, Keele University, Keele, UK.

Manandhar S, Pandey VP, Kazama F (2012) Application of Water Poverty Index (WPI) in Nepalese context: a case study of Kali Gandaki River Basin (KGRB) Water Resour Manag 24:89-107

Mayer AL (2008) Strengths and weaknesses of common sustainability indices for multidimensional systems, Environ Int 34:277-291

Molle F, Mollinga P (2003) Water poverty indicators: conceptual problems and policy issues. Water Policy 5:529-544

Pahl-Wostl C (2002) Participative and stakeholder-based policy design, evaluation and modelling processes. Integrated assessment 3(1):3-14

Pandey V, Manandhar S and Kazama F (2012) Water poverty situation of medium-sized river basins in Nepal. Water Resour Manag 26(9):2475-2489

Pérez-Foguet, A, Giné Garriga R. (2011) Analyzing Water Poverty in Basins. Water Resourc Manag 25(14):3595-3612

Revenga C (2005) Developing indicators of ecosystem condition using geographic information systems and remote sensing. Regional Environmental Change 5:205-214 
Shah T, van Koppen B (2006) Is India ripe for integrated resource management? Fitting water policy to national development policy. Econ and Pol Weekly 41(31):3413-3421

Singelton S (2009) Native People and Planning for Marine Protected Areas: How “Stakeholder" Processes Fail to Address Conflicts in Complex, Real-World Environments. Coastal Management, 37:421-440 Sullivan C (2002) Calculating the Water Poverty Index. World Development 30(7):1195-1210 Sullivan CA, Meigh JR, Giacamello AM, Fediw T, Lawrence P, Samad M, Mlote S, Hutton C, Allan JA, Schulze RE, Dlamini D, Cosgrove W, DelliPriscoli J, Gleick P, Smout I, Cobbing J, Calow R, Hunt D, Hussain A, Acreman MC, King J, Malomo S, Tate EL, O’Regan DO, Milner S, Steyl I (2003) The Water Poverty Index: Development and application at the community scale. Nat Resourc Forum (27):189-199

Sullivan CA, Meigh J (2004) Targeting attention on local vulnerabilities using an integrated index approach: the example of the Climate Vulnerability Index. Paper prepared for the Conference: Climate change: challenge or threat for water management. 27-29 September, 2004, Amsterdam

Sullivan CA, Meigh J (2007) Integration of the biophysical and social sciences using an indicator approach: Addressing water problems at different scales Water Resour Manag 21:111-128

Tippet J, Searle B, Pahl-Worst C, Rees Y (2005) Social learning in public participation in river basin management - early findings from HarMoniCOP European case studies. Environ Sci and Policy 8:287299

Ty TV, Sunada K, Ichikawa Y, Oishi S (2010) Evaluation of the state of water resources using modified water poverty index: a case study in the Srepok river basin, Vietnam-Cambodia Int J River Basin Manag 8(3-4):305-317

United Nations World Water Development Report (2003) Water for People, Water for Life. UNESCO and Berghahn Books, Barcelona

Van den Hove S (2006) Between consensus and compromise: acknowledging the negotiation dimension in participatory approaches. Land Use Policy 23:10-17 
Wilk J (2009) How do researchers view the role of local knowledge in natural resource management?

Journal of Environmental, Cultural, Economic and Social Sustainability 5(39):25-36

Wilk J, Jonsson A (2008) Using an integrated tool to promote sustainable rural development participatory modification of the Water Prosperity Index at village level in India, Proceedings of 2nd VHU Conference on Science for Sustainable Development. Uppsala: VHU, pp 95-102

\footnotetext{
${ }^{\mathrm{i}}$ Annual Average for Vidisha $(2003-2007)=1134$. Standardized. Min 580. Max 1634.

${ }^{\text {ii }}$ Co-efficient of variation $(2003-2007)=19 \%$. Standardized. Min 10\%. Max 50\%. Inverted.

iii Average of community annual ranking (1996-2006).

iv "White" Status for Vidisha. Average of community seasonal ranking based on incidence of water-borne illnesses. ${ }^{\mathrm{v}}$ Ratio of withdrawal/recharge. Vidisha $=14 . \mathrm{Min}=0$. Max $=189$. Inverted. $4 \%$ of farmers pump groundwater. Inverted.

${ }^{v i}$ Percentage of landowners that own irrigated land.

vii Average of community annual ranking (1996-2006).

${ }^{\text {viii }}$ As per Census of India, if a household has access to drinking water supplied from a tap or hand pump/ tube well situated within or outside the premises, it is considered as having access to safe drinking water.

ix Average distance $(\mathrm{m})$ to the nearest and second nearest public hand pumps calculated block-wise (see Figure X). Standardized. Min $=0$. Max $=150$. Inverted.

${ }^{x}$ This corresponds to percentage of water carried by women from Sullivan et al. (2003).

${ }^{x i}$ Village: $5 \mathrm{HHs}$ / public hand pump. Hamlet: $25 \mathrm{HHs} /$ public hand pump. Standardised. Min= 1. Max= 49 (Hamlet) and 26 (Village). Inverted.

xii $\%$ of land that is irrigated against sown area. Vidisha $=27$. Standardised. Max $=79$, Min $=0.4$.

xiii Vidisha $=97 / 1000$. Standardised. Min $=46$. Max $=145$. Inverted.

xiv Average for Madhya Pradesh.

${ }^{\mathrm{xv}} \mathrm{Lcpd}=$ litres per capita per day. Unstandardised for WPI. Standardised in WPI ${ }^{+}$. Min = 20 lpcd (World Bank, WHO and US Agency for International Development (in Gleick, 2002). Max =50 lcpd Gleick (1996).

${ }^{\mathrm{xvi}}$ Conflicts intensify in summer when water flow is limited.

xvii $\%$ of irrigated land to total land.

${ }^{\text {xviii }}$ Use for worship, medicine, fruits, fuel.
} 